\title{
Transcription Factors in Neuroendocrine Regulation: Rhythmic Changes in pCREB and ICER Levels Frame Melatonin Synthesis
}

\author{
Erik Maronde, ${ }^{1}$ Martina Pfeffer, ${ }^{1}$ James Olcese, ${ }^{2}$ Carlos A. Molina, ${ }^{3}$ Florence Schlotter, ${ }^{3}$ Faramarz Dehghani, ${ }^{1}$ \\ Horst-Werner Korf, ${ }^{1}$ and Jörg H. Stehle ${ }^{1}$ \\ ${ }^{1}$ Dr. Senckenbergische Anatomie, Institute for Anatomy II, Johann Wolfgang Goethe-University Frankfurt, 60590 Frankfurt, \\ Germany, 2/nstitute for Hormone and Fertility Research, University of Hamburg, 22529 Hamburg, Germany, and \\ 3Department of Obstetrics and Gynecology, University of Medicine and Dentistry of New Jersey, New Jersey Medical \\ School, Newark, New Jersey 07103-2714
}

Neurotransmitter-driven activation of transcription factors is important for control of neuronal and neuroendocrine functions. We show with an in vivo approach that the norepinephrine cAMP-dependent rhythmic hormone production in rat pineal gland is accompanied by a temporally regulated switch in the ratio of a transcriptional activator, phosphorylated CAMPresponsive element-binding protein (pCREB), and a transcriptional inhibitor, inducible cAMP early repressor (ICER). pCREB accumulates endogenously at the beginning of the dark period and declines during the second half of the night. Concomitant with this decline, the amount of ICER rises. The changing ratio

Neurotransmitter-driven activation of transcription factors (TFs) of the cAMP-signaling pathway is a widespread phenomenon in nervous tissue. In particular, the TFs cAMP-responsive elementbinding protein (CREB) (Montminy et al., 1990) and inducible cAMP early repressor (ICER) (Stehle et al., 1993) have been shown to operate selectively in time and space and often in an antagonistic way on cAMP-linked cellular phenomena (SassoneCorsi, 1998). In the rat pineal gland the activity state of the cAMP-signaling pathway determines the rhythmic synthesis of the hormone melatonin (Klein, 1985), suggesting that cAMPlinked TFs are part of regulatory mechanisms (Stehle, 1995; Florez and Takahashi, 1996; Foulkes et al., 1997).

A central oscillator located in the hypothalamic suprachiasmatic nucleus drives a nocturnally elevated release of norepinephrine (NE) from the sympathetic nerve endings (Drijfhout et al., 1996) that reaches the pineal gland (Klein et al., 1991; Korf, 1996). NE induces a large increase of cAMP levels in pinealocytes in vitro (Vanecek et al., 1985). cAMP is the essential second

Received Nov. 4, 1998; revised Feb. 5, 1999; accepted Feb. 11, 1999.

This work was supported by grants from the Deutsche Forschungsgemeinschaft (J.O., H.-W.K., and J.H.S.) and the August Scheidel-Stiftung (J.H.S.) and by Grant CA-69316 from the National Institutes of Health (NIH) (C.A.M.). We thank P. Ruth for help with the initial experiments, G. Schwoch (Göttingen, Germany) for the cPKA antibody, and D. C. Klein and J. L. Weller (NIH, Bethesda, MD) for the AA-NAT antibody. We thank D. C. Klein for helpful discussion and H. Wicht, I. Schneider-Hüther, and A. Samalekos for technical help.

Drs. E. Maronde and M. Pfeffer contributed equally to this work.

Correspondence should be addressed to Dr. Jörg H. Stehle, Dr. Senckenbergische Anatomie, Anatomisches Institut II, Johann Wolfgang Goethe-Universität, Theodor-Stern-Kai 7, 60590 Frankfurt, Germany.

Dr. Maronde's present address: Niedersächsisches Institut für Peptidforschung, Feodor-Lynen-Straße 31, 30625 Hannover, Germany.

Copyright (C) 1999 Society for Neuroscience $\quad 0270-6474 / 99 / 193326-11 \$ 05.00 / 0$ between PCREB and ICER shapes the in vivo dynamics in mRNA and, thus, protein levels of arylalkylamine- $N$ acetyltransferase, the rate-limiting enzyme of melatonin synthesis. Consequently, a silenced ICER expression in pinealocytes leads to a disinhibited arylalkylamine- $N$-acetyltransferase transcription and a primarily enhanced melatonin synthesis.

Key words: pineal gland; CREB (CAMP-responsive elementbinding protein); melatonin; arylalkylamine-N-acetyltransferase; transcription factor; ICER (inducible cAMP early repressor); circadian rhythm; antisense; cAMP signaling messenger for control of transcription and activity of the ratelimiting enzyme for melatonin synthesis, the arylalkylamine- $N$ acetyltransferase (AA-NAT) (Stehle, 1995; Klein et al., 1996). After the NE challenge, AA-NAT mRNA levels start to rise in vivo and in vitro within $1 \mathrm{hr}$ (Borjigin et al., 1995; Coon et al., 1995; Roseboom et al., 1996). Three to four hours later, AA-NAT mRNA levels in the rat pineal gland are 150-fold higher than control levels, succeeded by an increase of similar magnitude in AA-NAT enzymatic activity. Before the end of the night, AANAT mRNA levels decrease dramatically (Borjigin et al., 1995; Coon et al., 1995; Roseboom et al., 1996). Thus, two critical time domains exist in vivo within the dynamics of up- and downregulation in melatonin synthesis, (1) the postdusk domain and (2) the predawn domain.

During the postdusk domain, a temporal gap is evident between the NE-induced activation of the cAMP-signaling pathway and the stimulation of AA-NAT transcription and activity. In vitro studies demonstrated that the phosphorylation of the activating TF CREB at serine 133 (Gonzalez and Montminy, 1989) falls into this gap (Roseboom and Klein, 1995; Tamotsu et al., 1995). Notably, a functional CREB-binding site has recently been characterized as an AA-NAT promoter element (Foulkes et al., 1996; Baler et al., 1997).

The rapid decline of elevated AA-NAT mRNA levels in rat pineal gland during the predawn domain indicates a tuned impact of inhibiting TFs of the cAMP-signaling pathway, and indeed, $\mathrm{NE}$ elicits an increased transcription of a very potent inhibitor of cAMP-inducible genes, the TF ICER (Stehle et al., 1993).

To unravel molecular links between the cAMP-signaling pathway and the rhythmic AA-NAT transcription in the rat pineal gland, we initially investigated the levels of cAMP, the catalytic 
$\mathbf{a}$

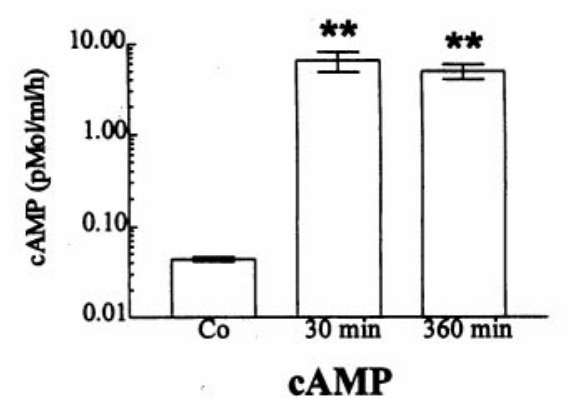

b

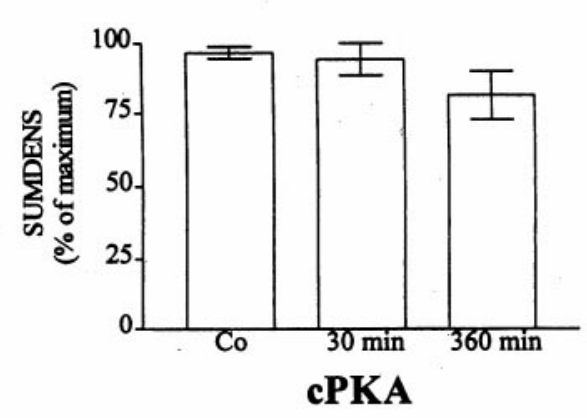

c

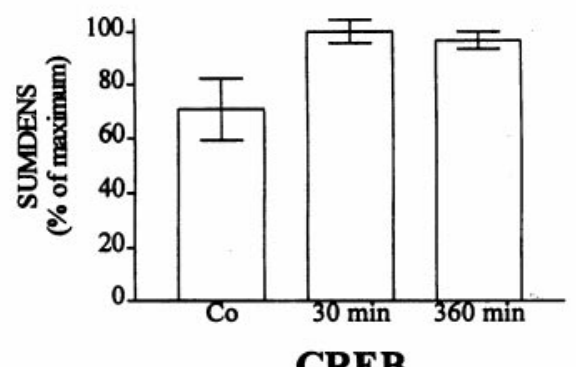

d

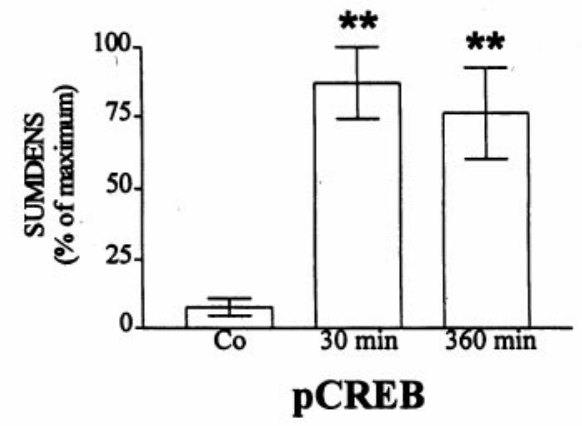

e

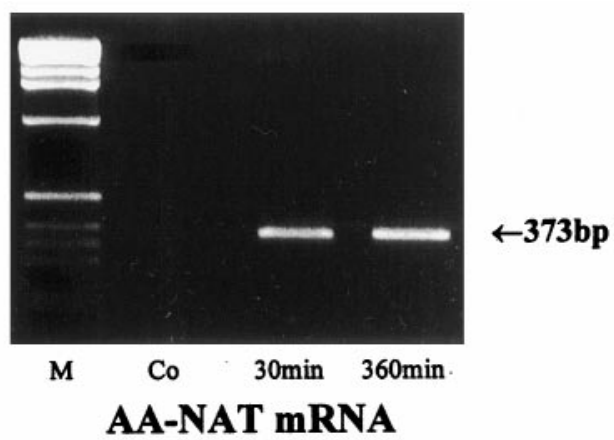

f

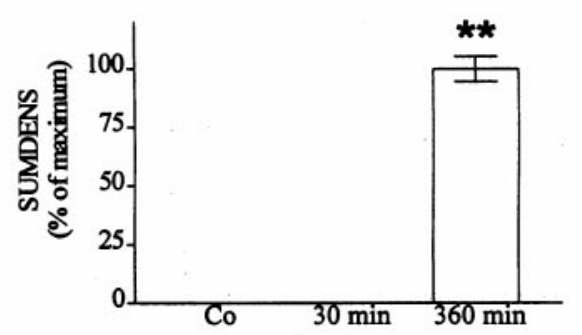

AA-NAT protein

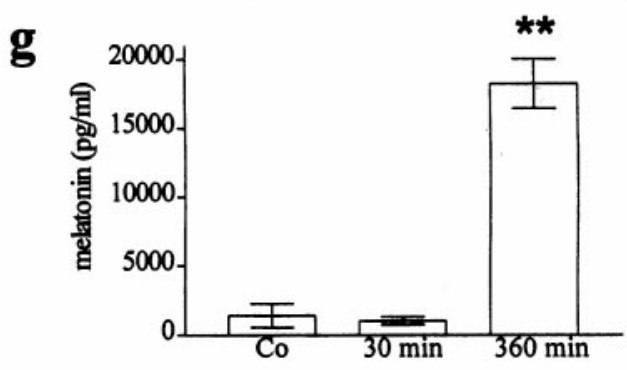

melatonin

$\mathbf{h}$

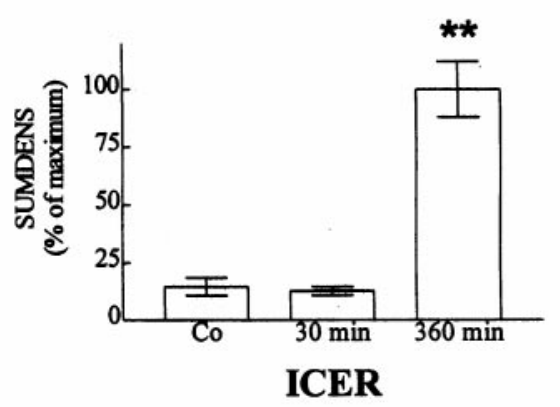

Figure 1. Sequential analysis of signaling events in rat pineal gland in vitro. Explanted rat pineal glands were stimulated with $\mathrm{NE}\left(10^{-7} \mathrm{M}\right)$ for $30 \mathrm{~min}$ or $6 \mathrm{hr} . b-d, f, h$, Semiquantitative analyses of SUMDENS values as analyzed from immunoblots $(n=3-7)$. $e$, RT-PCR analysis of RNA extracts using AA-NAT-specific primers. Equal loading was confirmed by coamplification of template cDNA with GAPDH primers (Pfeffer et al., 1998). $g$, Melatonin values analyzed from the culture medium by ELISA. $C o$, control; $M$, molecular weight markers. ** $p<0.001$ versus control.

subunit of the cAMP-dependent protein kinase (cPKA), CREB, phosphorylated CREB (pCREB), ICER and AA-NAT mRNA and protein, and melatonin. We detected $24 \mathrm{hr}$ rhythms for pCREB and ICER, distinctly out-of-phase, that gate the nocturnally elevated AA-NAT mRNA level and corroborated the inhibitory role of ICER within this neuroendocrine transduction in an in vitro approach.

\section{MATERIALS AND METHODS}

Animal maintenance, treatments, and tissue sampling. All animal experimentation reported in this manuscript was conducted in accordance with the Policy on the Use of Animals in Neuroscience Research and the Policy on Ethics as approved by the Society for Neuroscience. Male Wistar rats $(n=95 ; 150-250$ gm body weight $)$ were maintained under a standard 12:12 hr light/dark schedule [LD; lights off at Zeitgeber time 12 (ZT12)] with food and water available ad libitum. Rats were killed by 


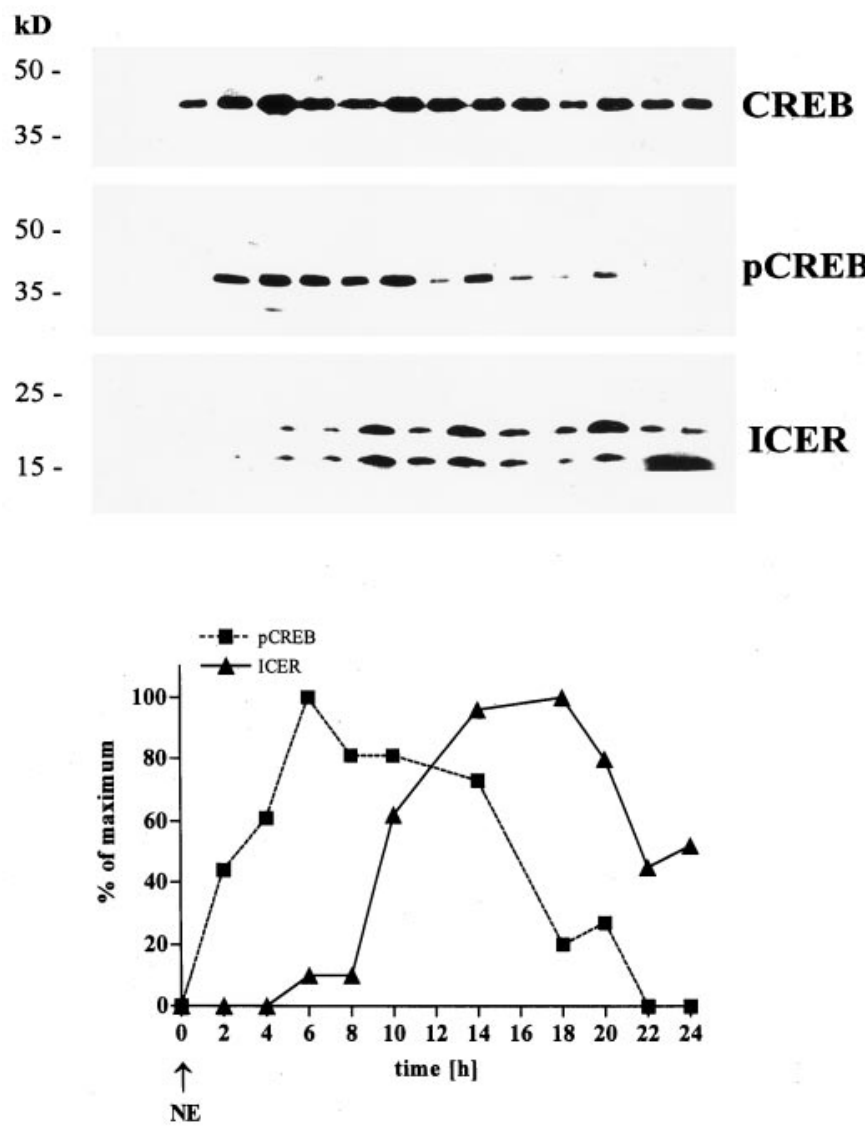

Figure 2. Twenty-four hour NE stimulation of explanted pineal glands. Top, Representative immunoblots for CREB, pCREB, and ICER in protein extracts from NE-stimulated rat pineal glands $\left(10^{-6} \mathrm{M}\right)$. Blots were run simultaneously with extracts from the same pineal gland. Protein sizes are indicated on the left. Bottom, Images from the top analyzed by semiquantitative densitometry. The obtained SUMDENS values were corrected for CREB signals. For comparison, values were normalized so that the peak SUMDENS values for PCREB (squares with dashed line) and ICER (triangles with solid line) equal $100 \%$.

decapitation under bright white light during the daytime or under dim red light (wavelength $>620 \mathrm{~nm}$ ) during nighttime at selected time points over a $24 \mathrm{hr}$ cycle according to the experimental paradigm. Additional animals $(n=18)$ were transferred from LD into constant darkness (DD) $1 \mathrm{~d}$ before the experiments and were killed at indicated time points under dim red light. Additional animals $(n=15)$ were acutely exposed to light in the middle of the night ( $6 \mathrm{hr}$ after lights off) and killed 30 min later. For experiments requiring unfixed material, brains were processed as described (Stehle et al., 1995; Pfeffer and Stehle, 1998).

In vitro culture of pineal glands or isolated pinealocytes. For the in vitro experiments, pineal glands were removed from adult male Wistar rats during early subjective light phase ( $n=52 ; 150-200 \mathrm{gm}$ body weight) as described (Tamotsu et al., 1995). At the end of the experiments, samples were either fixed in $4 \%$ paraformaldehyde for the immunocytochemical investigations or sonicated for protein gel electrophoresis (for details, see below).

Antibody preparation and immunocytochemical investigations. For immunocytochemical detection of pCREB and ICER in brain and pineal sections, animals were transcardially perfused with $4 \%$ paraformaldehyde, and brains were removed and processed as described (Brednow and Korf, 1998). Fixed cell preparations were incubated with a rabbit polyclonal pCREB antibody (Ginty et al., 1993) (lot 9190/001; 1:500; New England Biolabs, Beverly, MA), recognizing Ser-133-phosphorylated CREB and the phosphorylated form of the related protein ATF-1. Additionally, a rabbit polyclonal ICER antibody was used $(1: 60,000)$ that was raised against the whole ICER-II $\gamma$ protein (Razavi et al., 1998). Antibody specificity was assessed by incubating the diluted antibody overnight at $4^{\circ} \mathrm{C}$ with bacterially expressed ICER-II $\gamma$ peptide in 100 -fold excess before the immunohistochemical procedure. Binding of the antibody was visualized as described (Tamotsu et al., 1995). Second and third antibodies and all other chemicals were obtained from Sigma (Deisenhofen, Germany), unless indicated otherwise. Routinely, the fraction of pinealocytes in the cell preparations was identified by means of the cytoplasmic S-antigen immunoreaction and found to be $>95 \%$ (for details, see Tamotsu et al., 1995).

Immunoblotting. To obtain immunoblots from ex vivo and in vitro experiments, we sonicated tissue samples or cells directly in $50 \mu \mathrm{l}$ of sample buffer. Electrophoresis and blotting were done as described (Rittenhouse and Marcus, 1983; Szewcyk and Kozloff, 1985). The membranes were incubated with polyclonal antibodies against cPKA (1: $50,000)$ (Schwoch et al., 1980), pCREB (1:5000), ICER $(1: 100,000)$ (Razavi et al., 1998), and AA-NAT (serum 2500; 1:30,000; kind gift of Dr. D. C. Klein, National Institutes of Health, Bethesda, MD) (Gastel et al., 1998). To standardize semiquantitative optical density (OD) analyses, we stripped protein blots and reprobed the blots with a CREB antibody that detects total CREB irrespective of the phosphorylation state (1: 5000; New England Biolabs). The membranes were subsequently incubated with a horseradish peroxidase (HRP)-conjugated secondary antibody (New England Biolabs) diluted 1:100,000. The signals were detected by chemiluminescence (UltraSignal; Pierce, Rockford, IL). ICER antibody specificity was assessed by incubating the diluted antibody overnight at $4^{\circ} \mathrm{C}$ with bacterially expressed ICER-II $\gamma$ peptide in $250-, 25-$, and 2.5 -fold excess.

In situ hybridization. A partial rat AA-NAT cDNA (373 bp) was generated by PCR and subcloned, and ${ }^{35}$ S-labeled sense and antisense ribonucleotide probes were generated by in vitro transcription with $\mathrm{T} 3$ or T7 polymerase (Boehringer Mannheim, Mannheim, Germany) after plasmid linearization with HindIII or EcoRI, respectively, as described (Pfeffer and Stehle, 1998). In situ hybridization was performed according to published procedures (Stehle et al., 1993; Pfeffer and Stehle, 1998; Pfeffer et al., 1998).

Gel mobility shift analysis. Gel mobility shift assays and preparation of nuclear extracts were performed as described (Foulkes et al., 1991; Molina et al., 1993; Roseboom and Klein, 1995). Briefly, $10 \mu \mathrm{g}$ of nuclei extracted from six pineal glands was incubated with a synthetic $18 \mathrm{bp}$ oligonucleotide containing the rat somatostatin CRE $\left[5^{\prime}\right.$ CTTGGCTGACGTCAGAGA-3' (Stehle et al., 1993)] or with a synthetic 23 bp oligonucleotide containing the rat AA-NAT CRE [5'CCACCGATGACGCCAGCCCTCAG-3' (Baler et al., 1997)] (all primers were purchased from MWG Biotech, Munich, Germany) in a total volume of $20 \mu \mathrm{l}$ as described (Molina et al., 1993; Stehle et al., 1993). Oligonucleotides were end-labeled with $\left[\gamma_{-}{ }^{32} \mathrm{P}\right]$ ATP, using T4 polynucleotide kinase. To test for the presence of ICER among the nuclear proteins complexed with the AA-NAT CRE, we added the ICER antibody $(1 \mu l)$ to pineal extracts before gel mobility shift assays. To ensure equal loading, we determined protein concentrations in nuclear extracts before loading them onto $10 \%$ polyacrylamide gels (Foulkes et al., 1991; Molina et al., 1993; Roseboom and Klein, 1995).

Computer-assisted semiquantitative analysis of the immunocytochemical investigations. Data obtained by immunoblot and immunocytochemical experiments were analyzed semiquantitatively, using a computer-assisted image analysis system and a combined densito- and planimetric analysis (KS 300; Kontron, Eching, Germany) (Pfeffer et al., 1998; Wicht et al., 1999). The product of density and area of a given signal is called the SUMDENS value. In immunocytochemical preparations an additional correction for the total area covered by the cells was used; the resulting parameter is called corrSUMDENS (Pfeffer et al., 1998; Wicht et al., 1999). Amounts of detectable CREB protein in extracts from pineal glands varied only marginally after stimulation and did not fluctuate diurnally (see Results; see Figs. 2, 3). These observations are consistent with the current understanding of CREB as a housekeeping gene (Montminy et al., 1990). We therefore used the OD values derived from autoradiographic images of the CREB-specific band at $43 \mathrm{kDa}$ in the immunoblots as a quantitative marker for the amount of loaded total protein and corrected the OD values of pCREB- and ICER-specific bands, accordingly.

Transfection of pinealocytes. Primary pinealocytes were transfected with the eukaryotic expression vector pRcCMV (Invitrogen, San Diego, CA) carrying a PCR-generated partial cDNA of the ICER $5^{\prime}$-end in either the antisense (pICERas) or sense (pICERs) orientation as described (Pfeffer et al., 1998). Briefly, the pinealocyte culture medium was supplemented for $5 \mathrm{hr}$ with $20 \mu \mathrm{g}$ of the vector pRcCMV without insert, with pICERs, or with pICERas. Subsequently, cultures were washed and 


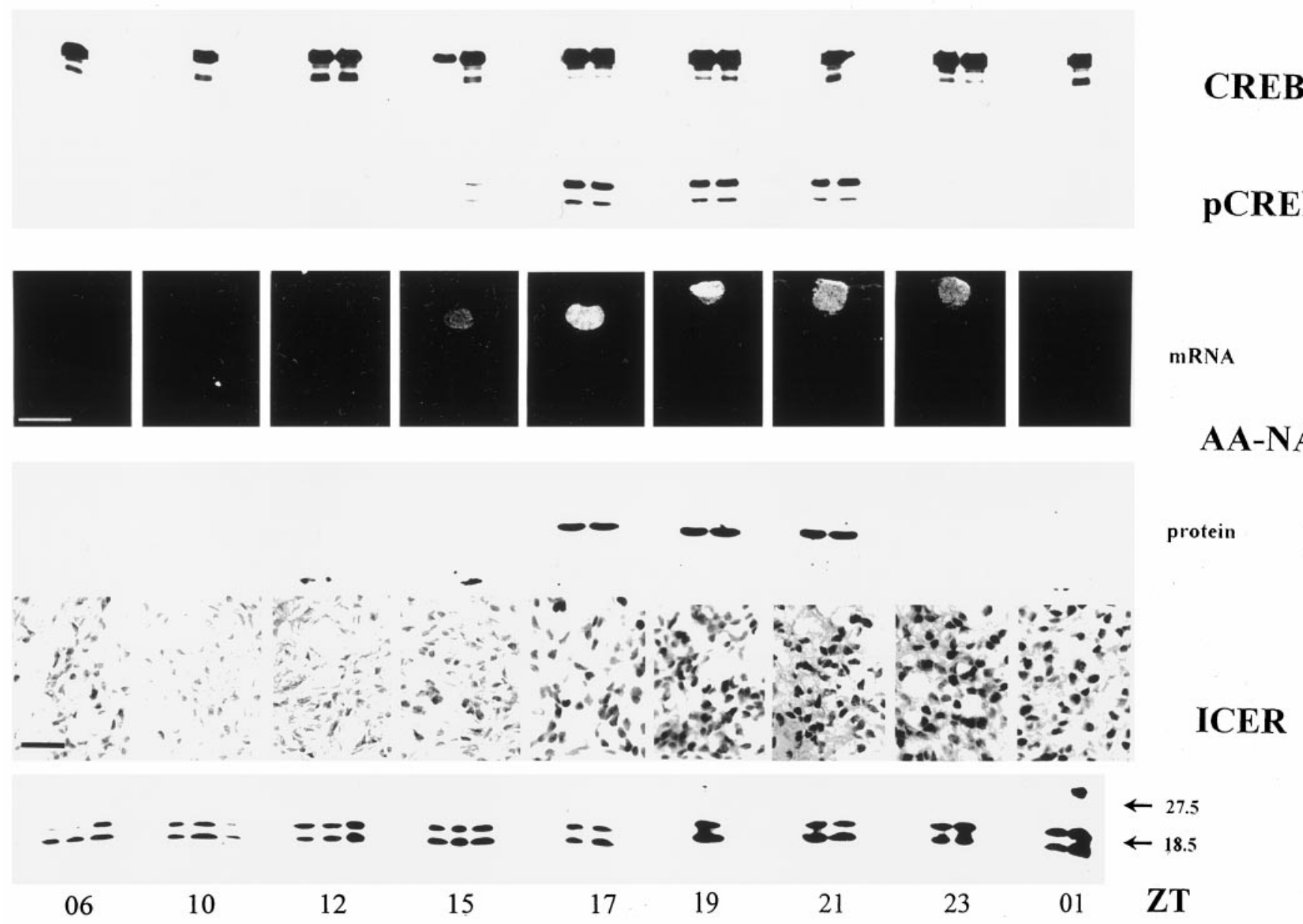

Figure 3. Diurnal rhythms in pCREB, AA-NAT, and ICER. Representative immunoblots for CREB, pCREB, AA-NAT, and ICER in rat pineal glands taken ex vivo at the indicated time points are shown. The two bands in the ICER immunoblots likely represent the isoforms ICER and ICER $\gamma$ (Molina et al., 1993; Foulkes et al., 1996; Razavi et al., 1998). In addition, autoradiographic images from a representative in situ hybridization with an antisense AA-NAT cDNA ribonucleotide probe and ICER immunocytochemical images of sections from rat pineal glands are shown. Animals were maintained under 12:12 hr light/dark conditions with lights off at ZT12. Scale bars: AA-NAT in situ hybridization, $200 \mu \mathrm{m}$; ICER immunocytochemistry, $20 \mu \mathrm{m}$.

after a recovery period of $16 \mathrm{hr}$ stimulated with $10^{-6} \mathrm{M} \mathrm{NE}$ for up to 24 hr. After stimulation, cell extracts were prepared by the freeze-and-thaw technique and frozen at $-80^{\circ} \mathrm{C}$ until further use for RNA extraction (Chomczynski and Sacchi, 1987). Melatonin secretion was analyzed by radioimmunoassay (see below).

Semiquantitative RT-PCR. RT-PCR was validated and performed as described (Pfeffer et al., 1998). The specific AA-NAT PCR was performed with $0.5-2 \mu \mathrm{l}$ of the RT-generated cDNA in a reaction volume of $100 \mu \mathrm{l}$ containing $1.5 \mu \mathrm{M}$ forward and reverse primer (see primers above). The PCR conditions were optimized to cycling conditions of denaturation at $95^{\circ} \mathrm{C}$ for $2 \mathrm{~min}, 25$ cycles for $1 \mathrm{~min}$ at $95^{\circ} \mathrm{C}, 1 \mathrm{~min}$ at $58^{\circ} \mathrm{C}$, and $1 \mathrm{~min}$ at $74^{\circ} \mathrm{C}$ and terminated at $74^{\circ} \mathrm{C}$ for $7 \mathrm{~min}$. Because agarose gel electrophoresis of PCR products indicated that the AA-NAT RT-PCR amplification was approximately quantitative between 25 and $75 \mathrm{ng}$ of template RNA, amounts within this range were used routinely. Subsequently, an additional PCR for the housekeeping gene glyceraldehyde3-phosphate-dehydrogenase (GAPDH) was conducted for each experiment to control for quantitative amplification conditions (for details, see Pfeffer et al., 1998). PCR products were electrophoresed, visualized by UV irradiation, and photodocumented.

Radioimmunoassays. Melatonin was measured either after extraction from trunk blood serum or in the medium collected from each well after termination of the experiment. Newly synthesized melatonin was measured by means of an ELISA based on a commercial radioimmunoassay (Osceola). The detection limit for melatonin in this assay is $1.5 \mathrm{pg} / \mathrm{ml}$ (for details, see Maronde et al., 1995). Extracellular cAMP was measured on the basis of a commercial radioimmunoassay with slight modi- fications (Olcese et al., 1997). For all experiments samples were collected in at least three independent experiments.

Statistical analysis. Data in all figures are expressed as the means $( \pm$ SEM) evaluated from at least three independent experiments with two to five samples each as indicated in the figure legends. Statistical analysis (Graph Pad, San Diego, CA) involved either a Student's $t$ test or an ANOVA with subsequent Bonferroni tests for multiple comparisons with $p \leq 0.05$ as the criterion of significance.

\section{RESULTS}

\section{The cAMP-signaling cascade in rat pineal gland: a sequential analysis in vitro}

The NE-induced increase in cAMP levels stimulates phosphorylation of the activating transcription factor CREB within minutes in explanted rat pineal glands and pinealocytes (Roseboom and Klein, 1995; Tamotsu et al., 1995). The subsequent increase in AA-NAT expression and melatonin biosynthesis shows high values at the latest after $6 \mathrm{hr}$ (Roseboom et al., 1996). Therefore, we first analyzed molecular events in cultured rat pineal glands at these two selected time points. The production rate of cAMP was increased $>200$-fold within 30 min after NE stimulation (Fig. 1a; $p<0.001 ; n=3)$. No further increase in cAMP production rate 
a

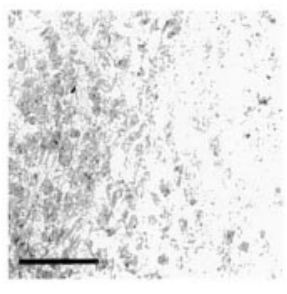

17

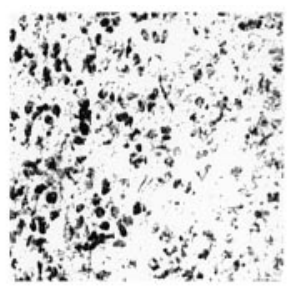

18

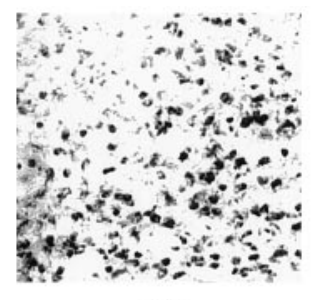

19

b

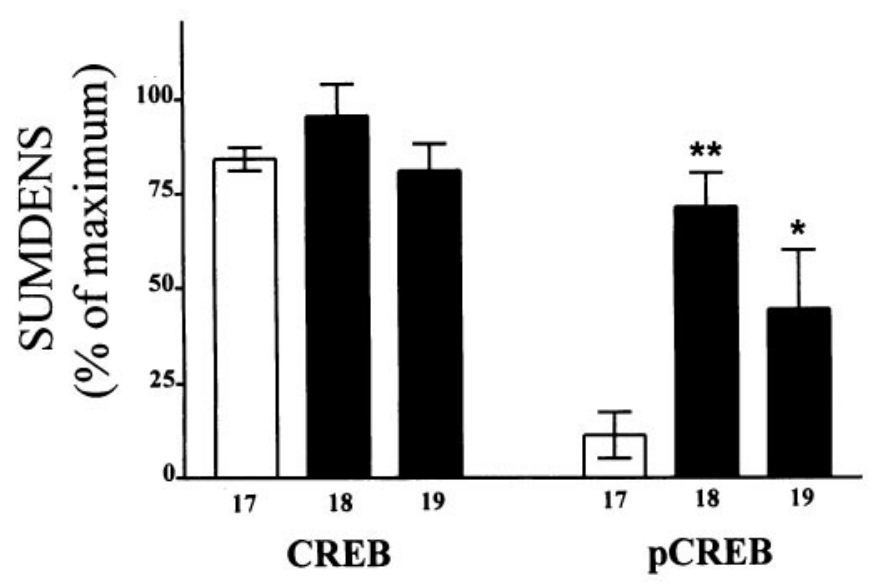

\section{DD}
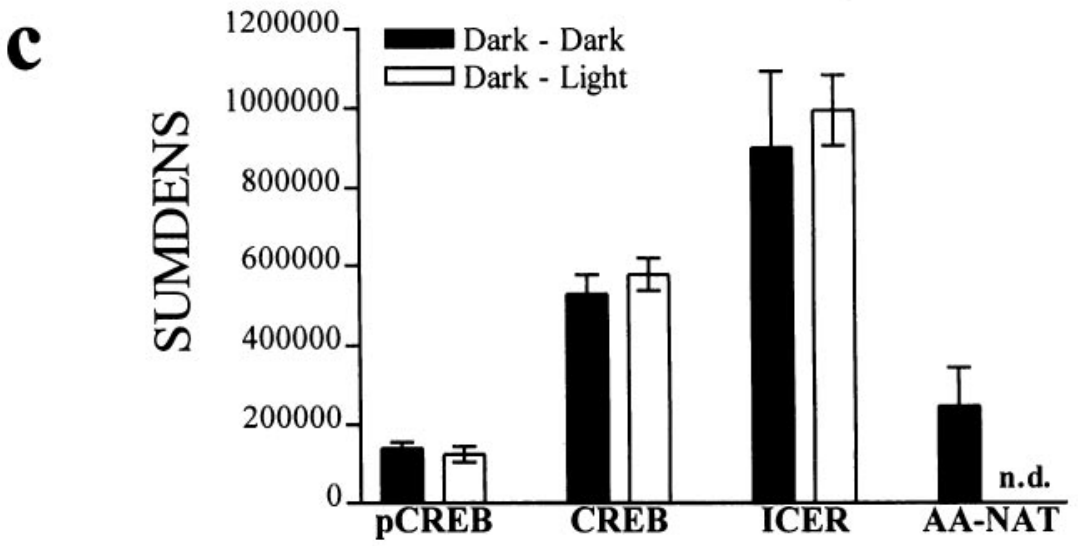

Figure 4. Phosphorylation of CREB in rat pineal gland is a circadian event. $a$, The phosphorylation of CREB occurs under conditions of 12:12 hr light/dark $(L D)$ shortly after the onset of the dark period (lights off at ZT12), as shown with immunocytochemical images from sections of rat pineal glands taken ex vivo at the indicated time points. Scale bar, $50 \mu \mathrm{m} . b$, The onset of CREB phosphorylation persists under constant darkness $(D D)$. For comparison of CREB with pCREB, SUMDENS values are normalized from immunoblot analyses $(n=3)$ so that peak values equal $100 \%$. The open bar (11.5) represents a time point during subjective daytime; the closed bars represent time points at subjective night. $c$, A 30 min exposure of animals to light during subjective nighttime (ZT18) leads to the expected decline of AA-NAT protein levels (rightmost column) (see also Gastel et al., 1998); however, CREB, pCREB, and ICER levels remain unaltered. n.d., Not detectable.

could be observed within the next 360 min of NE stimulation. The amount of cPKA remained unaltered after stimulation (Fig. $1 b)$. However, analysis of nuclear extracts revealed a considerable nuclear translocation of cPKA within 30 min after the NE challenge (E. Maronde and H.-W. Korf, unpublished observations). The OD analysis of signals obtained from immunoblots revealed that overall levels of total CREB in pineal extracts varied only marginally after stimulation (Fig. 1c). In contrast NE induced a robust and maximal pCREB immunoreaction within $30 \mathrm{~min}$ in immunoblots from cultured hemidissected pineal glands (Fig. $1 d$; $p<0.001$ ) (see also Roseboom and Klein, 1995; Tamotsu et al.,
1995). The maximal amount of pCREB was estimated semiquantitatively by dividing the SUMDENS values for $\mathrm{pCREB}$ by the corresponding values for total CREB obtained in the same blot after stripping of the signal and reprobing. Such calculations showed that maximally $15 \%$ of the total CREB present in rat pinealocytes is phosphorylated both in vitro under NE stimulation and in vivo at night. Thus, a maximally stimulated cAMP pathway leads to only a relatively small increase in the amount of pCREB as compared with the available amount of CREB (see Fig. $4 c$; compare SUMDENS values for pCREB with that for CREB from animals maintained in darkness). The immunoblot 


\section{a}

\section{b}

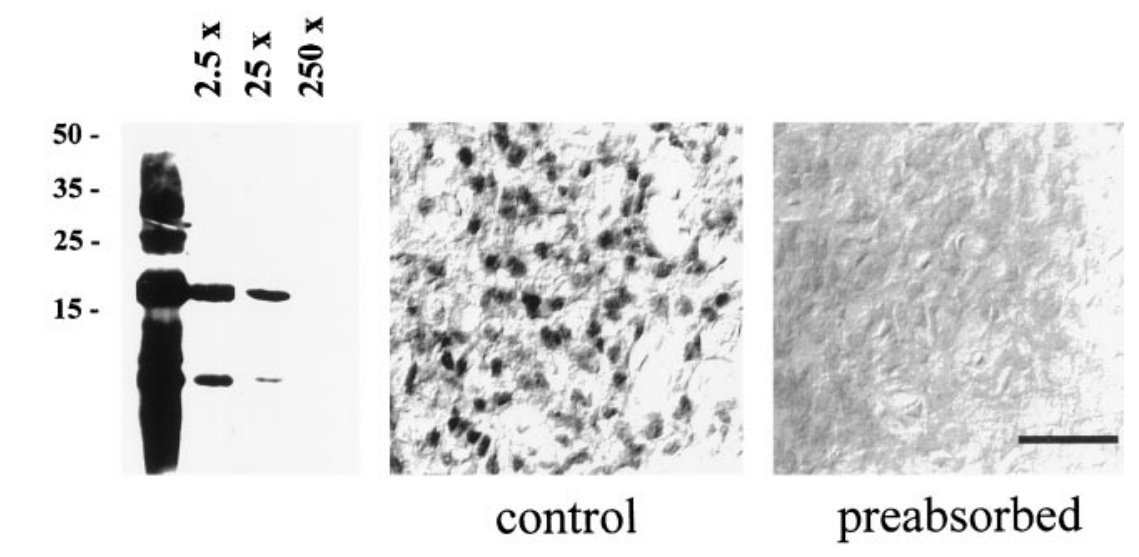

C

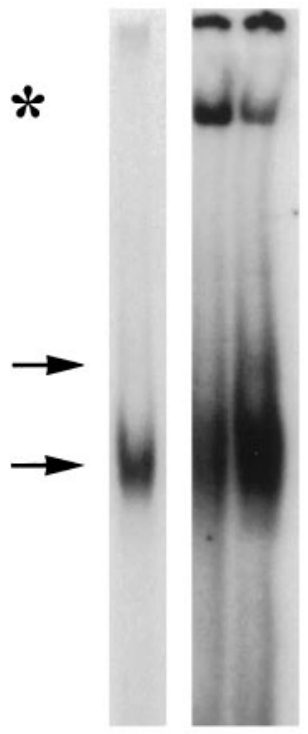

$\begin{array}{lll}1 & 2 & 3\end{array}$

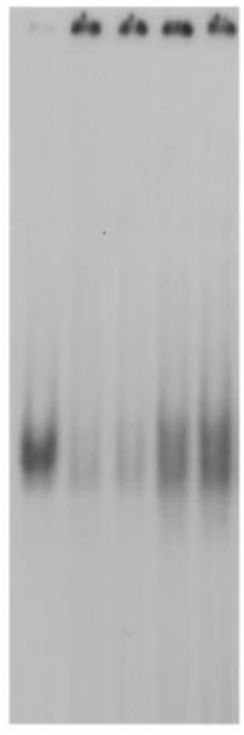

$\begin{array}{lllll}4 & 5 & 6 & 7 & 8\end{array}$

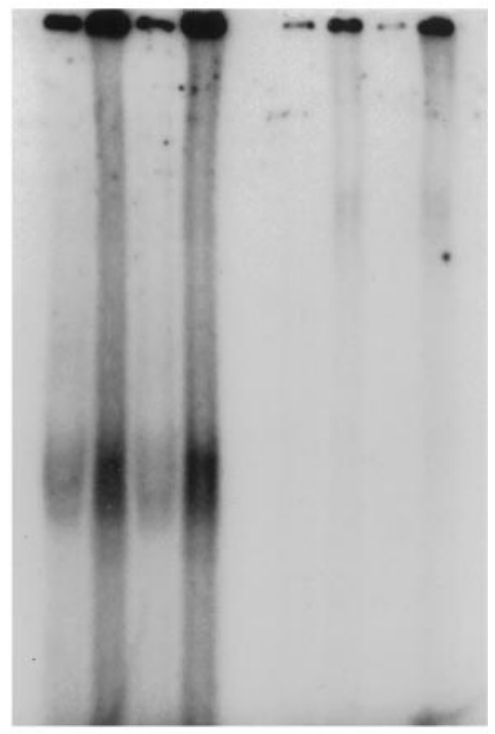

$9101112 \quad 13141516$
Figure 5. Characterization of the ICER antibody $a, b$, ICER immunoreaction could be abolished by preincubation of the antibody with the antigenic peptide in a dose-dependent manner in immunoblots ( $a$ ) (2.5- to 250-fold excess of ICER protein) and immunohistochemical preparations $(b)(250$ fold excess of ICER protein). Similar results were obtained in two additional experiments. Scale bar, $20 \mu \mathrm{m} . c$, Gel mobility shift analyses with nuclear extracts obtained from rat pineal glands incubated with a labeled AA-NAT CRE always revealed a specific band of retarded mobility (lower arrow) that comigrated with bacterially generated ICERII $\gamma$ (compare lanes 1, 4 with lanes 2, 3, 7-12). An additional ICER-specific signal of unknown quality is indicated by the upper arrow. Coincubation with the ICER antibody generated an additional low mobility complex (lanes 2, 3; indicated by a star). Excess of unlabeled AA-NAT CRE $(100 \times)$ suppressed specific binding (compare lanes 5, 6 with lanes 7,8 ). Notably, the labeled AA-NAT CRE (lanes 9-12) has a higher affinity for nuclear extracts as compared with that of a labeled somatostatin-CRE (lanes 13-16) (lanes 9, 11, 13, $15,1 \mu \mathrm{g}$ of nuclear extract; lanes 10, 12, 14, 16, 10 $\mu \mathrm{g}$ of nuclear extract). Similar results were obtained from four separate nuclear extract preparations. analysis revealed that the antibody detects predominantly pCREB (43 kDa; also Fig. 2). A distinct additional band, smaller than that of pCREB, was occasionally observed that may account for the phosphorylated form of the related transcription factor ATF-1 (New England Biolabs protocol). Our OD analysis showed that this additional band, which always fluctuates in parallel to that of pCREB, represents $<10 \%$ of the overall signal. It was blocked by preabsorption of the antibody with the antigenic peptide (Tamotsu et al., 1995). All results suggest pCREB immunoreactivity as a reliable marker for an activated cAMP-signaling pathway in rat pineal gland.

RT-PCR for AA-NAT mRNA amplified a fragment of the expected size (373 bp; Fig. 1e; also in situ hybridization in Fig. 3) and revealed a large increase in transcript number $30 \mathrm{~min}$ after stimulation that persisted throughout the experiment, confirming a previous report using Northern blot analysis (Roseboom et al., 1996). AA-NAT protein (Fig. $1 f ; p<0.001$ ) (Gastel et al., 1998), melatonin synthesis (Fig. 1 $g ; p<0.001$ ) (Rüppel and Olcese, 1991; Maronde et al., 1997), and ICER immunoreactivity (Fig. $1 h ; p<0.001)$ were elevated after $6 \mathrm{hr}$ of NE stimulation. In the ICER immunoblots, two specific bands were detected that correspond in size to the various ICER and ICER $\gamma$ isoforms described (Desdouets et al., 1995; Lalli and Sassone-Corsi, 1995; Foulkes et al., 1996; Razavi et al., 1998) (see also Figs. 2, 3).

To investigate late molecular events within pineal signaling, we stimulated explanted pineal glands with $\mathrm{NE}$ and monitored the dynamics of CREB phosphorylation and ICER protein levels over the following $24 \mathrm{hr}$ (Fig. 2). Despite the continuous presence of NE, we regularly observed a rapid decline in pCREB levels 10 hr after stimulation started, possibly because of increased phosphatase activity (Hagiwara et al., 1992). ICER protein levels began to rise $4 \mathrm{hr}$ after NE stimulation. The amount of ICER protein reached maximum values after $14 \mathrm{hr}$ of NE stimulation and declined after $18 \mathrm{hr}$ of stimulation, supporting the autoreg- 


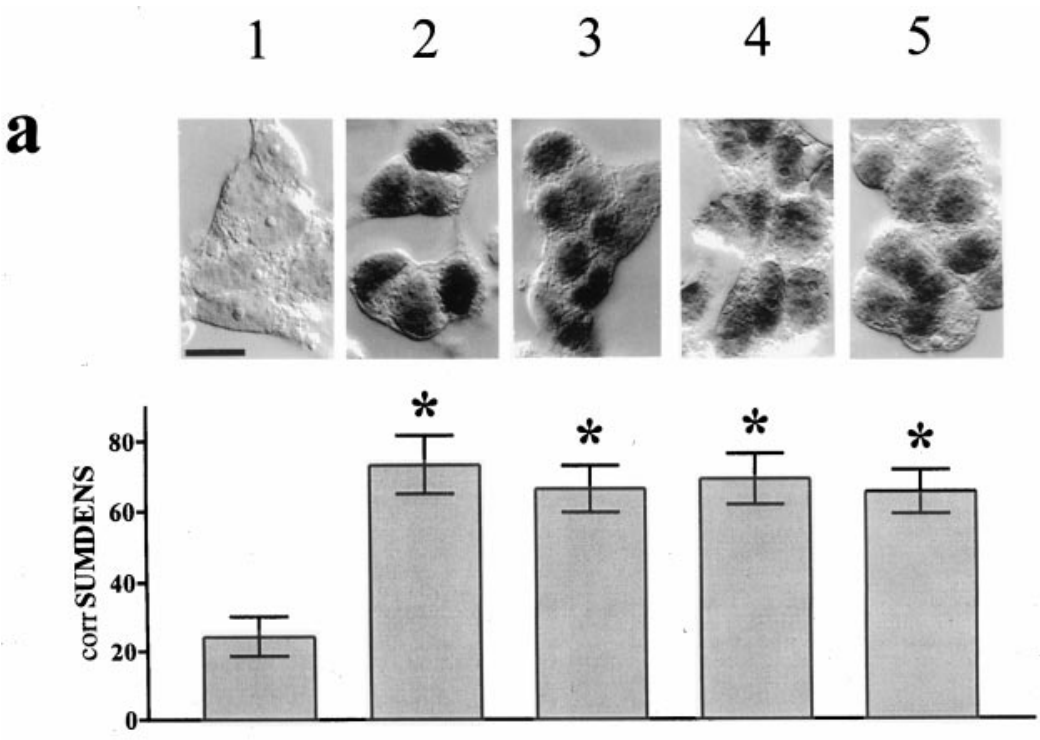

\section{pCREB}

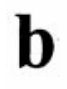

Figure 6. Silencing of ICER in rat pinealocytes primarily diminishes inducibility in ICER immunoreactivity. Top panels, NE induces nuclear pCREB $(a)$ and ICER $(b)$ immunoreactivity in isolated pinealocytes (compare columns 1 and 2). Bottom panels, The SUMDENS values from semiquantitative image analyses $(n=12)$ corrected for the total area covered by the cells [corrSUMDENS (Wicht et al., 1999)] are shown. Similar results were obtained with the $\beta_{1^{-}}$ adrenergic agonist isoproterenol (data not shown). Column 1, Unstimulated pinealocytes (control). $a$, The NE-induced increase in pCREB immunoreactivity in pinealocyte preparations (compare columns 1 and 2) is independent of transfected DNA (compare columns 2 and 3-5). b, Silencing ICER (column 5, pICERas) decreases NE-induced ICER immunoreactivity, as compared with that of NE-stimulated pinealocytes that were untransfected (column 2) or transfected with control DNA (column 3, pRcCMV) or with pICERs (column 4).
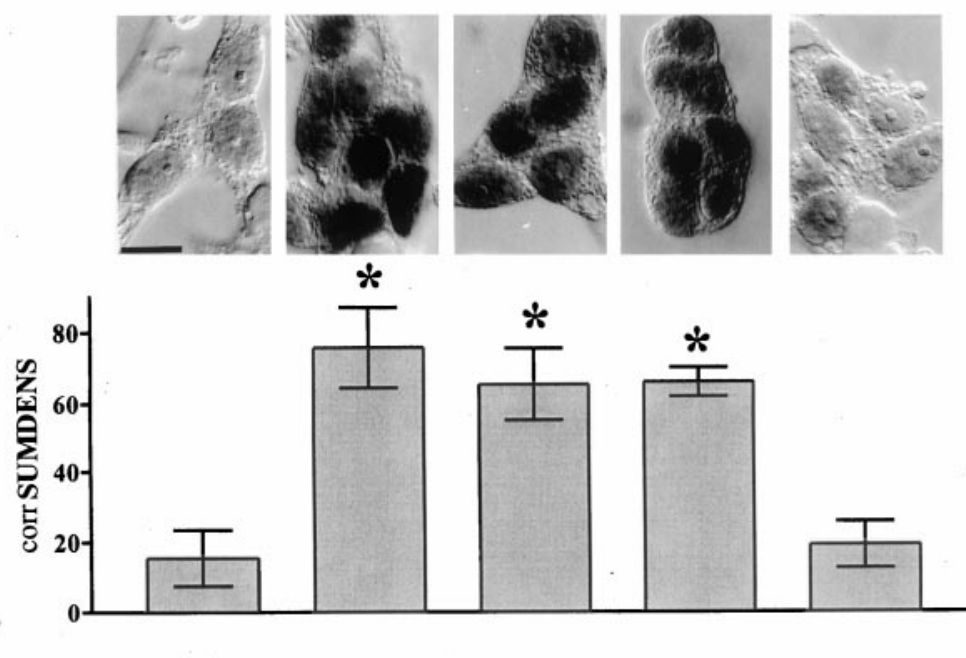

\section{ICER}

ulatory mechanisms for this transcription factor suggested previously (Molina et al., 1993; Stehle et al., 1993; Foulkes et al., 1997).

\section{Rhythm in CREB phosphorylation, AA-NAT mRNA, and AA-NAT and ICER protein levels in rat pineal gland in vivo}

Because of the sequence of molecular events observed in our in vitro experiments, we reasoned that the nocturnal increase in $\mathrm{NE}$ release from intrapineal sympathetic nerve fibers (Drijfhout et al., 1996) elicits CREB phosphorylation at the beginning of the night. Indeed, we found dramatic changes in pCREB levels over a $24 \mathrm{hr}$ light/dark period, whereas no day/night variation in CREB protein levels was seen (see Figs. 3, 8). pCREB levels were low during the light phase and highly increased within $5 \mathrm{hr}$ after lights off (ZT17). Individual time course experiments showed temporal variability in the rise of pCREB levels in both the immunochemi- cal (Fig. 3; $n=8$ ) and immunohistochemical (Fig. $4 a ; n=6$ ) analyses of CREB phosphorylation in rat pineal gland. The onset of an increased phosphorylation of CREB varied considerably from one to the other experiment between 30 and 180 min after lights off (see Figs. 3, 4a, 8). It is worth mentioning that a delayed onset in CREB phosphorylation was always accompanied by a time-matched delay in elevated melatonin synthesis (see Figs. 1, 8). We attribute these observations to interindividual differences, e.g., different suprachiasmatic nucleus (SCN) activity patterns between animals. The semiquantitative densitometric analysis of different individual protein blots revealed a dynamic change in CREB phosphorylation with elevated values between $30 \mathrm{~min}$ and $9 \mathrm{hr}$ after the beginning of the dark period (see Figs. 3, 4a, 8) as compared with daytime levels. The decrease in the amount of pCREB was predictable and occurred always well before the end 
of the dark period (see Figs. 3, 8). The day/night switch in CREB phosphorylation was preserved in animals kept under constant darkness (Fig. 4b), indicating an endogenous circadian regulatory mechanism. This endogenous rise in the amount of $\mathrm{pCREB}$ in rat pineal gland was blocked when animals were injected with the $\beta_{1}$-adrenergic antagonist propranolol before the onset of darkness, when the gland was chronically deprived of its sympathetic input by ganglionectomy or when rendered arrhythmic by bilateral destruction of the SCN (data not shown).

AA-NAT mRNA levels in rat pineal gland were analyzed by in situ hybridization (Fig. 3) as described (Pfeffer and Stehle, 1998). The semiquantitative densitometric analysis $(n=4)$ of the autoradiographic images from rat coronal brain sections revealed a sharp increase in the amount of AA-NAT mRNA after the beginning of the dark period. Maximum values for AA-NAT mRNA occurred $6 \mathrm{hr}$ after the onset of darkness. AA-NAT mRNA levels started to decline $3 \mathrm{hr}$ before the end of the dark phase and reached daytime values before the beginning of the following light period (see Figs. 3, 8). The dynamics of this decline is slightly different from that in a previous report using Northern blot analysis (Roseboom et al., 1996) and may be attributable to the different photoperiodic regimes used in the two studies [14:10 hr (Roseboom et al., 1996) and 12:12 hr (this study)]. AA-NAT protein levels showed a very similar pattern as compared with the phosphorylation of CREB (see Figs. 3, 8). The observed decline in AA-NAT protein occurred before the decline in AA-NAT mRNA levels, confirming a previous report (Roseboom et al., 1996) and indicating a post-translational mechanism (Gastel et al., 1998) of AA-NAT protein degradation in vivo.

The ex vivo immunoblot analysis showed a drastic increase in ICER protein $7 \mathrm{hr}$ after the beginning of the dark period that stayed elevated thereafter into the early light phase (Fig. 3). The amount of the larger ICER isoform was increased up to eightfold at nighttime as compared with daytime values. The nuclear ICER immunoreactivity present at the dark/light transition declined gradually as the light phase progressed and was low at the end of the day. Similarly, strong nuclear staining for ICER protein was already present in almost all pinealocytes $5 \mathrm{hr}$ after the onset of darkness and still increased during the second half of the night (Fig. 3). It is noteworthy that the temporal onset of ICER immunoreactivity in rat pineal gland was rather constant between individual experiments (see Figs. 3, 8). This indicates that rhythmic ICER expression is controlled more tightly by the NE challenge than the rhythmic phosphorylation of CREB (see above).

A 30 min exposure of animals to light during the dark period (6 hr after lights off) led to a rapid decline in AA-NAT activity (Klein and Weller, 1972) and protein (Fig. 4c), possibly because of proteasomal proteolysis of the AA-NAT protein (Gastel et al., 1998). Unlike AA-NAT protein, the amount of pCREB, CREB, and ICER protein was not affected by the light treatment (Fig. 4c).

\section{Characterization of the ICER antibody}

Preincubation of the ICER antibody with the bacterially generated antigenic peptide abolished ICER signals in both immunoblot (Fig. 5a) and immunohistochemical (Fig. 5b) preparations. Gel mobility shift analyses with nuclear extracts of rat pineal gland and a labeled AA-NAT CRE consequently revealed a specific band of retarded mobility (Fig. 5c, lower arrow) that comigrated with bacterially generated ICER-II $\gamma$ (Fig. $5 c$, compare lanes 1, 4 with lanes 2, 3, 7-12). Minor bands could also be observed (Fig. 5c, upper arrow) that may account for AA-NAT CRE binding to related TFs (Baler and Klein, 1995). Coincuba- tion with the ICER antibody generated a low mobility complex (Fig. 5c, lanes 2, 3, star), an observation consistent with a previously published characterization of other TFs binding to the AA-NAT CRE (Baler et al., 1997). Excess of unlabeled AA-NAT CRE $(100 \times)$ competed with specific binding (Fig. $5 c$, compare lanes 5, 6 with lanes 7, 8). The labeled AA-NAT CRE (Fig. 5c, lanes 9-12) showed higher binding to nuclear extracts as compared with that of a labeled somatostatin-CRE (Fig. 5c, lanes 13-16) (Razavi et al., 1998) (lanes 9, 11, 13, 15, $1 \mu \mathrm{g}$ of nuclear extract; lanes 10, 12, 14, 16, $10 \mu \mathrm{g}$ of nuclear extract). Similar results were obtained from three separate nuclear extract preparations.

\section{$\mathbf{a}$}

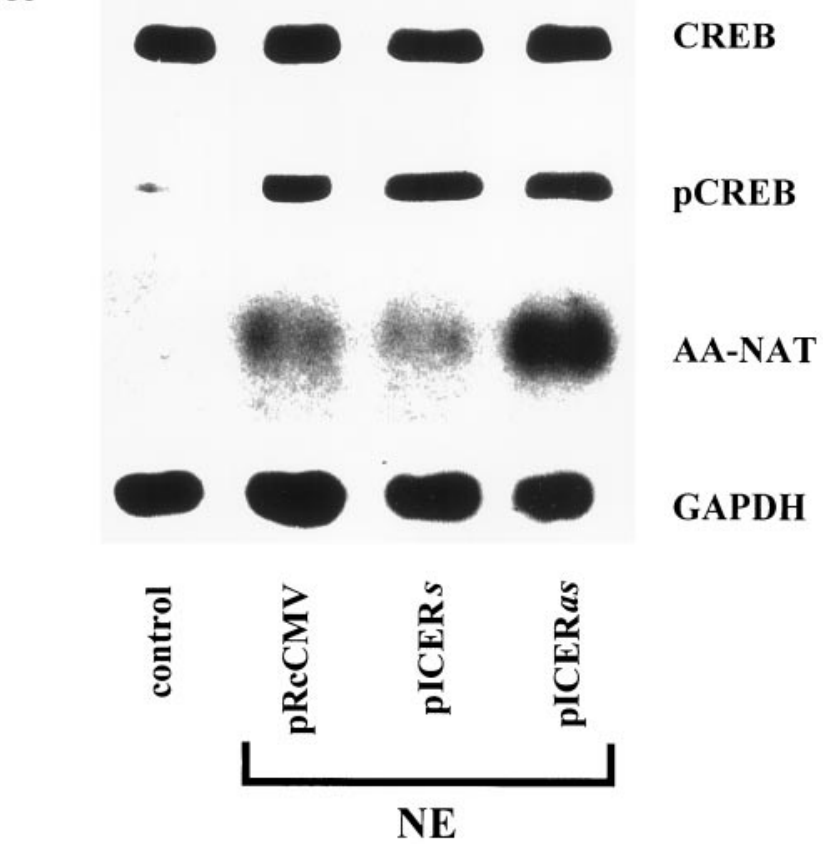

b

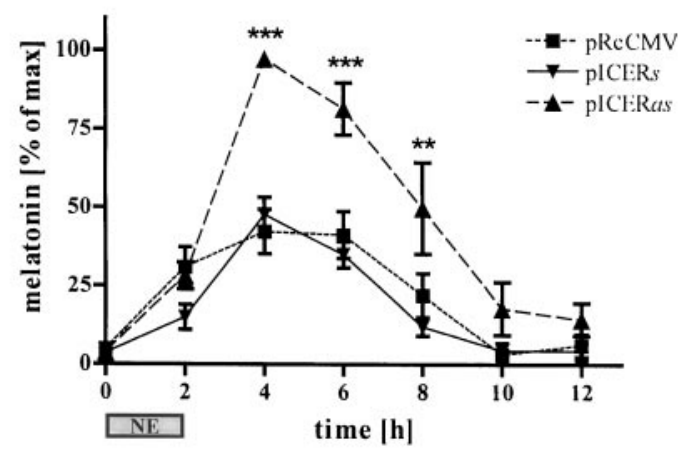

Figure 7. NE-induced AA-NAT mRNA levels and melatonin synthesis are disinhibited in pICERas-transfected pinealocytes. $a$, CREB and pCREB immunoblots from unstimulated (control) and stimulated (NE, $10^{-6} \mathrm{M} ; 5 \mathrm{hr}$ ) pinealocytes transfected with control DNA (pRcCMV), pICERs, or pICERas are shown. The amount of pCREB protein is highly induced in transfected and NE-stimulated cells (columns 2-4), as compared with control. Semiquantitative analysis of autoradiographic images from Northern blots probed for AA-NAT mRNA and corrected for the GAPDH signal revealed a fivefold superinduction in pICERastransfected cells (column 4) as compared with controls (columns 2, 3). b, NE-induced $\left(10^{-6} \mathrm{M} ; 2 \mathrm{hr} ; n=7\right)$ melatonin synthesis in pinealocytes is primarily increased in amplitude by silencing ICER. For equalizing differences between experiments in the absolute amounts of net melatonin synthesis, data are normalized so that the peak values equal $100 \%$. ${ }^{* *} p<$ $0.01 ; * * p<0.001$ versus the basal value at $0 \mathrm{hr}$. 
$\mathbf{a}$

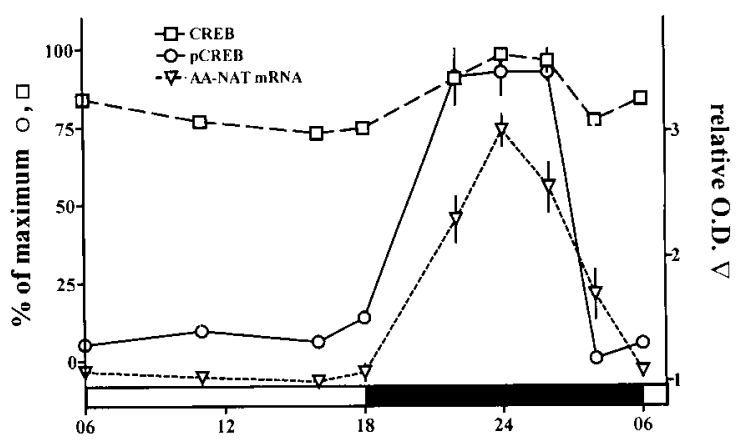

b

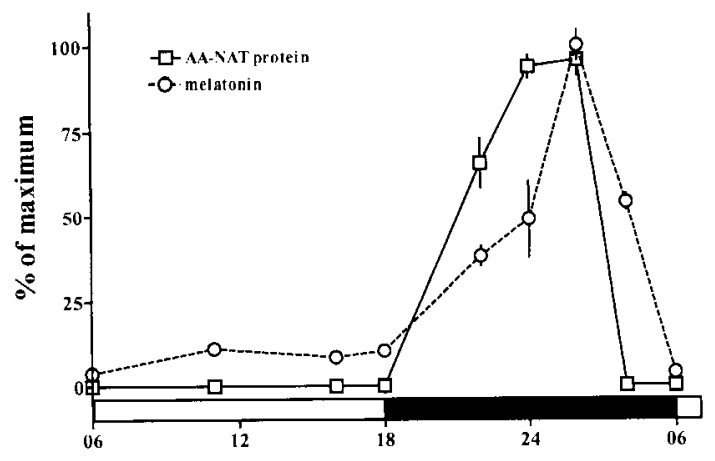

c

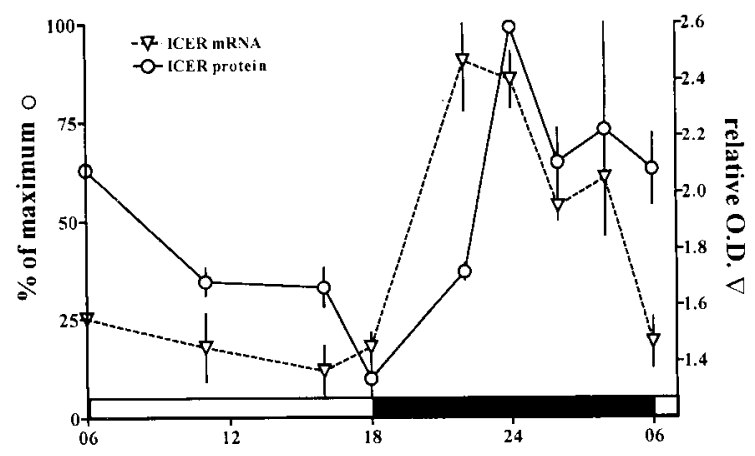

Figure 8. Diurnal rhythms in elements determining melatonin synthesis in rat pineal gland. $a$, SUMDENS values for CREB (squares with dashed line) and pCREB (circles with solid line) from immunoblot analyses. For comparison, values were normalized so that the peak SUMDENS values for pCREB and CREB equal 100\%. The semiquantitative analysis for AA-NAT mRNA (triangles with small dashed line) from in situ hybridization was corrected against the background signal and hybridization signal obtained with the sense AA-NAT probe. $b$, SUMDENS values for AANAT protein (squares with solid line) and melatonin synthesis (circles with dashed line). For comparison, values were normalized so that the peak SUMDENS values for AA-NAT and maximum melatonin values equal $100 \%$. c , Semiquantitative analysis of ICER mRNA (triangle with dashed line) as revealed by in situ hybridization. The values were corrected against the background signal and hybridization signal obtained with the sense ICER probe. SUMDENS values for ICER protein (circles with solid line) were normalized so that peak SUMDENS values equal $100 \%$.

\section{Transfection of primary pinealocyte cultures}

NE stimulation resulted in a strong nuclear staining for pCREB and ICER (Fig. 6, compare columns 1 and 2). Transfection of pinealocytes with a given construct did not affect NE-induced phosphorylation of CREB (Figs. $6 a, 7 a$ ). Transfection of pinealocytes with the vector carrying a partial ICER cDNA in antisense orientation (pICERas) greatly diminished NE-induced ICER immunoreactivity as compared with that of cells transfected with pICERs or the vector only (pRcCMV) (Fig. 6b). In unstimulated cells no AA-NAT mRNA and only a very low pCREB level were detectable. Stimulation of pICERas-transfected pinealocytes with $\mathrm{NE}$ resulted in a greatly enhanced AA-NAT mRNA level as compared with that of pICERs- or vector-transfected pinealocytes (Fig. 7a). The NE-induced melatonin synthesis showed an almost twofold superinduction after $4 \mathrm{hr}$ when pinealocytes were transfected with pICERas as compared with that of vector- or pICERs-transfected cells (Fig. 7b). Similar time course dynamics were obtained with the $\beta_{1}$-adrenergic agonist isoproterenol $\left(10^{-7}\right.$ $\mathrm{M} ; n=2)$ or forskolin $\left(10^{-2} \mathrm{M} ; n=2\right)$ (data not shown).

\section{DISCUSSION}

The $24 \mathrm{hr}$ rhythm of CREB phosphorylation in rat pineal gland is the first in vivo description of a neuronally driven, transient activation of this TF in cells of the CNS (Fig. 8). The accumulation of a cAMP-dependent intermediate - a phosphorylated (nuclear) protein - that bridges the time gap between adrenergic stimulation and the rise in transcription in rat pineal gland was postulated as early as 1977 (Winters et al., 1977). In vivo, pCREB levels stay elevated throughout the first half of the night, indicating the demand of a maintained high pool of the activated transcription factor for the nocturnally elevated pineal metabolism. These observations support the notion of a causal relationship between elevated levels of pCREB and an increased transcription of cAMP-inducible genes in the rat pineal gland in general (Stehle et al., 1993; Stehle, 1995; Pfeffer et al., 1998) and of the AA-NAT gene in particular (Borjigin et al., 1995; Roseboom et al., 1996).

The intensities of CREB- and pCREB-immunoreactive bands in parallel immunoblots of pineal protein extracts reveal an interesting insight into the stoichiometric activation of the cAMP-signaling pathway. Like in other systems, CREB in the rat pineal gland represents a constitutively expressed gene, whose transcriptional impact is primarily independent of de novo protein synthesis (Montminy et al., 1990; Crosson et al., 1996). Because the CREB antibody is antigenic against CREB and pCREB protein, the fraction of post-translationally modified CREB after stimulation can be determined; when AA-NAT transcription has reached high values, the pCREB fraction is at most $15 \%$ of the total amount of CREB in pinealocytes. This indicates that a minor fraction of post-translationally modified transcription factor is sufficient to mediate a full stimulation of AA-NAT transcription and, thus, to override the inhibitory impact of ICER on the AA-NAT CRE. The low amount of phosphorylated CREB as compared with the total amount of CREB may explain the notorious difficulties that we have had in detecting the circadian rhythm in CREB phosphorylation in the rat pineal gland. The high amount of unphosphorylated CREB protein in the rat pineal gland may serve to compensate for the demonstrated low efficiency of the cPKA to phosphorylate CREB at Ser-133 (Hagiwara et al., 1992, 1993). Additionally, the large pool of unphosphorylated CREB might ensure a broad dynamic range in CREB phosphorylation, in accordance with an animal's environmental and physiological situation.

During the postdusk domain, the ratio between activating and inhibiting transcription factors in the rat pineal gland is in favor of a transcriptional stimulation because the drastically increased amounts of pCREB override ICER protein levels. As the night progresses, the intrapineal pool of pCREB declines despite a persisting NE challenge. This dephosphorylation of pCREB is 
possibly related to increased amounts and/or activities of protein phosphatases (Hagiwara et al., 1992; E. Maronde and H. W. Korf, unpublished observations). In conjunction with the decrease of pCREB at this stage of the night, steadily increasing ICER protein levels gain influence, thereby attenuating cAMPinducible gene transcription. This link has been shown previously for the transcription rate of ICER itself (Stehle et al., 1993) and of the $\beta_{1}$-adrenergic receptor (Pfeffer et al., 1998). Notably, rhythmic transcription can lead to immediate [AA-NAT (Borjigin et al., 1995; Roseboom et al., 1996)] or delayed changes in functional protein [ $\beta_{1}$-adrenergic receptor (Pfeffer et al., 1998)]. Additional mechanisms like alternative splicing [ICER (Foulkes et al., 1991; Molina et al., 1993; Stehle et al., 1993)], alternative translation start [ICER (Gellersen et al., 1997)], post-translational modifications [CREB (Gonzalez and Montminy, 1989)], or proteolytic degradation [ICER (Folco and Koren, 1997)] can modulate TF efficiency. Still, ICER can affect AA-NAT transcription because we show complexing of the AA-NAT CRE with ICER. Furthermore, AA-NAT mRNA levels and melatonin synthesis increased drastically after the selective silencing of ICER in rat pinealocytes, possibly because of a disinhibited AA-NAT transcription. Notably, the NE-induced phosphorylation of CREB remained unaffected in pinealocytes transfected with the antisense ICER construct. Thus, liberating pCREB from its nuclear competitor ICER results in a hormonal superinduction. Principally, pCREB and ICER can scale the relative transcription rate of the AA-NAT gene by heterodimerization (de Groot and Sassone-Corsi, 1993; Desdouets et al., 1995) or by a direct competition for the CRE element in the AA-NAT promoter. It should be noted, however, that additional TFs have been described in rat pineal gland [AP-1 (Carter, 1994), Fra-2 (Baler and Klein, 1995), and CRX (Li et al., 1998)] with a temporal dynamics similar to that shown here for the phosphorylation of CREB. These TFs may complement the action of pCREB.

Our data provide strong evidence that the temporally regulated variation in the ratio of PCREB and ICER shapes the diurnal rhythm in AA-NAT transcription and that this rhythm provides a basis for the diurnal variation in AA-NAT protein levels and activity. Thus, one level of AA-NAT regulation is defined by a stable diurnal rhythm in transcription pattern, on which, however, post-transcriptional regulatory mechanisms are superimposed to allow rapid changes on a minute-to-minute basis. One mechanism for these rapid changes in AA-NAT activity may be proteasomal proteolysis. Indeed, this mechanism holds true for the acute light-induced inactivation of AA-NAT activity at nighttime (Gastel et al., 1998), but it does not affect pCREB or ICER levels (this study). Our finding that AA-NAT was hardly present at ZT23 despite detectable amounts of AA-NAT mRNA suggests that proteasomal proteolysis acts as an inactivating posttranscriptional mechanism also under a normal light/dark cycle.

In conclusion, our study provides a conceptual framework to understand the molecular basis of rhythmic neuroendocrine transduction; NE-dependent activation of the cAMP-signaling pathway in rat pineal gland affects (1) the very rapid posttranslational modification of preexisting TFs like the phosphorylation of CREB (Roseboom and Klein, 1995; Tamotsu et al., 1995; Korf et al., 1996), (2) the control of AA-NAT protein and activity by rapid post-translational modifications, and (3) the slower increase in the transcription and abundance of inducible TFs (Stehle et al., 1993; Stehle, 1995; Foulkes et al., 1997). The mammalian pineal gland will continue to serve as an excellent model system to understand TF-directed up- and downregulation of cAMP-inducible gene expression, to unravel concerted transcriptional and post-transcriptional interactions, and to assess their importance for the rhythmic synthesis and release of neurohormones and neurotransmitters.

\section{REFERENCES}

Baler R, Klein DC (1995) Circadian expression of transcription factor Fra-2 in the rat pineal gland. J Biol Chem 270:27319-27325.

Baler R, Covington S, Klein DC (1997) The rat arylalkylamine $N$-acetyltransferase gene promoter: cAMP activation via a cAMPresponsive element-CCAAT complex. J Biol Chem 272:6979-6985.

Borjigin J, Wang MM, Snyder SH (1995) Diurnal variation in mRNA encoding serotonin $N$-acetyltransferase in the pineal gland. Nature 378:783-785.

Brednow K, Korf HW (1998) Morphological and immunocytochemical features of the pineal organ of $\mathrm{C} 3 \mathrm{H}$ and $\mathrm{C} 57 \mathrm{BL}$ mice at different stages of postnatal development. Cell Tissue Res 292:521-530.

Carter DA (1994) A daily rhythm of activator protein-1 activity in the rat pineal gland is dependent upon trans-synaptic induction of jun- $B$. Neuroscience 62:1267-1278.

Chomczynski P, Sacchi N (1987) Single-step method of RNA isolation by acid guanidinium thiocyanate-phenol-chloroform extraction. Anal Biochem 162:156-159.

Coon SL, Roseboom PH, Baler R, Weller JL, Namboodiri MAA, Koonin EV, Klein DC (1995) Pineal serotonin $N$-acetyltransferase: expression cloning and molecular analysis. Science 270:1681-1683.

Crosson SM, Davies GF, Roesler WJ (1996) Cyclic AMP-stimulated accumulation of the cAMP response element binding protein can occur without changes in gene expression. Biochem Biophys Res Commun 227:915-920.

de Groot RP, Sassone-Corsi P (1993) Hormonal control of gene expression: multiplicity and versatility of cyclic adenosine $3^{\prime}, 5^{\prime}$ monophosphate-responsive nuclear regulators. Mol Endocrinol 10:145-153.

Desdouets C, Matesic G, Molina C, Foulkes NS, Sassone-Corsi P, Brechot C, Sobczak-Thebot J (1995) Cell cycle regulation of cyclin A gene expression by the cyclic AMP-responsive transcription factors CREB and CREM. Mol Cell Biol 15:3301-3309.

Drijfhout WA, van der Linde S, Kooi C, Grol B, Westerink BHC (1996) Norepinephrine release in the rat pineal gland: the input from the biological clock measured by in vivo microdialysis. J Neurochem 66:748-755.

Florez JC, Takahashi JS (1996) Biological rhythms and the pineal gland. In: Comprehensive human physiology, Vol 1 (Greger R, Windhorst U, eds), pp 1199-1214. Berlin: Springer.

Folco EJ, Koren G (1997) Degradation of the inducible cAMP early repressor (ICER) by the ubiquitin-proteasome pathway. Biochem $\mathbf{J}$ 328:37-43.

Foulkes NS, Borrelli E, Sassone-Corsi P (1991) CREM gene: use of alternative DNA-binding domains generates multiple antagonists of cAMP-induced transcription. Cell 64:739-749.

Foulkes NS, Borjigin J, Snyder SH, Sassone-Corsi P (1996) Transcriptional control of circadian hormone synthesis via the CREM feedback loop. Proc Natl Acad Sci USA 93:14140-14145.

Foulkes NS, Borjigin J, Snyder SH, Sassone-Corsi P (1997) Rhythmic transcription: the molecular basis of circadian melatonin synthesis. Trends Neurosci 20:487-492.

Gastel JA, Roseboom PH, Rinaldi PA, Weller JL, Klein DC (1998) Melatonin production: proteasomal proteolysis in serotonin $N$-acetyltransferase regulation. Science 279:1358-1360.

Gellersen B, Kempf R, Telgmann R (1997) Human endometrial stromal cells express novel isoforms of the transcriptional modulator CREM and up-regulate ICER in the course of decidualization. Mol Endocrinol 11:97-113.

Ginty DD, Kornhauser JM, Thompson MA, Bading H, Mayo KE, Takahashi JS, Greenberg ME (1993) Regulation of CREB phosphorylation in the suprachiasmatic nucleus by light and a circadian clock. Science 260:238-241.

Gonzalez GA, Montminy M (1989) Cyclic AMP stimulates somatostatin gene transcription by phosphorylation of CREB at serine 133. Cell 59:675-680.

Hagiwara M, Alberts A, Brindle P, Meinkoth J, Feramisco J, Deng T, Karin M, Shenolikar S, Montminy M (1992) Transcriptional attenua- 
tion following cAMP induction requires PP-1-mediated dephosphorylation of CREB. Cell 70:105-113.

Hagiwara M, Brindle P, Harootunian A, Armstrong R, Rivier J, Vale W, Tsien R, Montminy M (1993) Coupling of hormonal stimulation and transcription via the cyclic AMP-responsive factor CREB is rate limited by nuclear entry of protein kinase A. Mol Cell Biol 13:4852-4859.

Klein DC (1985) Photoneural regulation of the mammalian pineal gland. In: Photoperiodism, melatonin and the pineal (Evered D, Clark S, eds), pp 38-56. London: Pitman.

Klein DC, Weller JL (1972) Rapid light-induced decrease in pineal serotonin $N$-acetyltransferase activity. Science 177:532-533.

Klein DC, Moore RY, Reppert SM (1991) Suprachiasmatic nucleus: the mind's clock (Klein DC, Moore RH, Reppert SM, eds), pp 1-467. New York: Oxford UP.

Klein DC, Roseboom PH, Coon SL (1996) New light is shining on the melatonin rhythm enzyme - the first postcloning view. Trends Endocrinol Metab 7:106-112.

Korf HW (1996) Innervation of the pineal gland. In: Series on the autonomic nervous system (Burnstock G, ed), Vol 10, Autonomicendocrine interactions (Unsicker K, ed), pp 129-180. Amsterdam: Harwood.

Korf HW, Schomerus C, Maronde E, Stehle JH (1996) Signal transduction in the rat pineal organ: $\mathrm{Ca}^{2+}, \mathrm{pCREB}$, and ICER. Naturwissenschaften 83:535-543.

Lalli E, Sassone-Corsi P (1995) Thyroid-stimulating hormone (TSH)directed induction of the CREM gene in the thyroid gland participates in the long-term desensitization of the TSH receptor. Proc Natl Acad Sci USA 92:9633-9637.

Li X, Chen S, Wang Q, Zack DJ, Snyder SH (1998) A pineal regulatory element (PIRE) mediates transactivation by the pineal/retina-specific transcription factor CRX. Proc Natl Acad Sci USA 95:1876-1881.

Maronde E, Middendorff R, Mayer B, Olcese J (1995) The effect of NO-donors in bovine and rat pineal cells: stimulation of cGMP and cGMP-independent inhibition of melatonin synthesis. J Neuroendocrinol 7:207-214.

Maronde E, Middendorff R, Telgmann R, Taskén K, Hemmings B, Müller D, Olcese J (1997) Melatonin synthesis in the bovine pineal gland is regulated by cyclic AMP-dependent protein kinase type II. J Neurochem 68:770-777.

Molina CA, Foulkes NS, Lalli E, Sassone-Corsi P (1993) Inducibility and negative autoregulation of CREM: an alternative promotor directs the expression of ICER, an early response repressor. Cell 75:1-20.

Montminy MR, Gonzalez GA, Yamamoto KK (1990) Regulation of cAMP-inducible genes by CREB. Trends Neurosci 13:184-188.

Olcese J, McArdle CA, Middendorff R, Greenland K (1997) Pituitary adenylate cyclase-activating peptide and vasoactive intestinal peptide receptor expression in immortalized LHRH neurons. J Neuroendocrinol 9:937-943.

Pfeffer M, Stehle JH (1998) Ontogeny in transcriptional regulation of the arylalkylamine- $N$-acetyltransferase in rat pineal gland. Neurosci Lett 248:163-166.
Pfeffer M, Kühn R, Krug L, Korf HW, Stehle JH (1998) Rhythmic variation in $\beta_{1}$-adrenergic receptor mRNA levels in rat pineal gland: circadian and developmental regulation. Eur J Neurosci 10:2896-2904.

Razavi R, Ramos JC, Yehia G, Scotter F, Molina CA (1998) ICER-II $\gamma$ is a tumor suppressor that mediates the antiproliferative activity of cAMP. Oncogene 17:3015-1019.

Rittenhouse J, Marcus F (1983) Peptide mapping by polyacrylamide gel electrophoresis after cleavage at aspartyl-prolyl peptide bonds in sodium-duodecyl sulfate-containing buffers. Anal Biochem 138:442-448.

Roseboom PH, Klein DC (1995) Norepinephrine stimulation of pineal cyclic AMP response element-binding protein phosphorylation: primary role of a $\beta$-adrenergic receptor/cyclic AMP mechanism. Mol Pharmacol 47:439-449.

Roseboom PH, Coon SL, Baler R, McCune SK, Weller JL, Klein DC (1996) Melatonin synthesis: analysis of the more than 150 -fold nocturnal increase in serotonin $N$-acetyltransferase messenger ribonucleotide acid in the rat pineal gland. Endocrinology 137:3033-3044.

Rüppel R, Olcese J (1991) Bovine pinealocytes in monolayer culture: studies on the adrenergic regulation of melatonin synthesis. Endocrinology 129:2655-2662.

Sassone-Corsi P (1998) Coupling gene expression to cAMP signalling: role of CREB and CREM. Int J Biochem Cell Biol 30:27-38.

Schwoch G, Hamann A, Hilz H (1980) Antiserum against the catalytic subunit of adenosine $3^{\prime}, 5^{\prime}$-cyclic monophosphate-dependent protein kinase. Biochem J 192:223-230.

Stehle JH (1995) Pineal gene expression: dawn in a dark matter. J Pineal Res 18:179-190.

Stehle JH, Foulkes NS, Molina CA, Simonneaux V, Pevet P, SassoneCorsi P (1993) Adrenergic signals direct rhythmic expression of transcriptional repressor CREM in the pineal gland. Nature 356:314-320.

Stehle JH, Foulkes NS, Pevet P, Sassone-Corsi P (1995) Developmental maturation of pineal gland function: synchronized CREM inducibility and adrenergic stimulation. Mol Endocrinol 9:706-716.

Szewcyk B, Kozloff LM (1985) A method for the efficient blotting of strongly basic proteins from sodium duodecyl sulfate-polyacrylamide gels to nitrocellulose. Anal Biochem 150:403-407.

Tamotsu S, Schomerus C, Stehle JH, Roseboom PH, Korf HW (1995) Norepinephrine-induced phosphorylation of the transcription factor CREB in isolated rat pinealocytes: an immunocytochemical study. Cell Tissue Res 282:219-226.

Vanecek J, Sugden D, Weller J, Klein DC (1985) Atypical synergistic $\beta_{1}$ - and $\alpha_{1}$-adrenergic regulation of adenosine $3^{\prime}, 5^{\prime}$-monophosphate in cultured rat pinealocytes. Endocrinology 116:2167-2173.

Wicht H, Maronde E, Olcese J, Korf HW (1999) A semiquantitative image-analytical method for the recording of dose-response curves in immunocytochemical preparations. J Histochem Cytochem 47:411-417.

Winters KE, Morrissey JJ, Loos PJ, Lovenberg W (1977) Pineal protein phosphorylation during serotonin $N$-acetyltransferase induction. Proc Natl Acad Sci USA 74:1928-1931. 